\title{
Progress on Ares First Stage Propulsion
}

\author{
Alex S. Priskos, First Stage Element Manager \\ Thomas J. Williams, Deputy First Stage Element Manager \\ Fred Brasfield, Project Manager \\ Michael Jacobs, Deputy Project Manager \\ Ares Projects Office \\ Marshall Space Flight Center \\ Huntsville, AL 35812
}

\begin{abstract}
The National Aeronautics and Space Administration (NASA) Ares Projects Office (APO) is continuing to make progress toward the final design of the first stage propulsion system for the Ares I crew launch vehicle and the Ares V cargo launch vehicle. Ares I and Ares V will provide the space launch capabilities necessary to fulfill NASA's exploration strategy of sending human beings to the Moon, Mars, and beyond. As primary propulsion for both the Ares I and Ares V, the Space Shuttle-derived Reusable Solid Rocket Motor (RSRM) is one of the first and most important components to be tested. The first flight of Ares I, called Ares I-X, will occur in April 2009. The Ares I-X flight will use a combination of flight and simulation hardware to obtain data on controlling the long and narrow crew launch vehicle configuration.
\end{abstract}

The test will use a four-segment RSRM from the Shuttle inventory and a fifth spacer segment to simulate the size and weight of the operational five-segment motor that will be used on later flights. Manufacturing work has begun on the fifth space segment. The upper stage, Orion crew exploration vehicle, and launch abort system will all be replaced with simulator hardware. Ares I-X will be controlled by Atlas $\mathrm{V}$ avionics adapted to control the first stage. That hardware is undergoing hardware-in-the-loop testing in a contractor-provided systems integration laboratory (SIL) and will complete its critical design review (CDR) in December 2007. Drogue and main parachute drop tests have also been conducted successfully at Yuma Proving Grounds, allowing the First Stage Element team to proceed with fabricating parachutes for Ares I-X. The Ares I-X flight test will be the first flight test for the parachutes as well. A series of preliminary design technical interchange meetings is being conducted prior to the Ares I-X CDR in January 2007 to ensure readiness for the flight.

A series of preliminary design activities associated with each booster subsystem has been the focus of much activity in 2007. These events will culminate in a formal preliminary design review in 2008. Subsystems and component specifications will be developed, associated analyses and drawings will be evaluated for technical adequacy given the system requirements that have been baselined.

The first stage has been undergoing a series of trade studies to determine means for upgrading booster performance and reducing operational costs. Performance improvement studies have included a change from polybutadiene acrylonitrile (PBAN) propellant to hydroxyl-terminated polybutadiene (HTPB); from aluminum to composite motor casings; and optimized or upgraded propellant grain and nozzle structures. Some or all of these changes could result in a block upgrade to the Ares I first stage, after becoming the standard configuration for the Ares V. The cost reduction studies included a change from reusable or recoverable boosters to completely expendable boosters; changing from hydrazine-powered to more environmentally friendly electrohydrostatic actuators (EHAs) on the thrust vector control (TVC) system; and changing the location of the separation plane to reduce the likelihood of recontact upon booster separation. The expendability trade study resulted in a decision to retain the recoverable boosters, as the new hardware costs significantly outweighed the potential operational cost savings due to reduced ground 
operations. Likewise, due to cost considerations, the team recommended continued use of the existing hydrazine-powered actuators for the TVC system. The separation plane location for Ares I is still being studied, with results to be announced in early 2008 .

In short, the Ares launch vehicles' first stage is building upon NASA's close familiarity with this Shuttle-derived system, while continuing to seek out improvements for long-term exploration. 
Nomenclature

$A P O=$ Ares Projects Office

$C D R=$ Critical Design Review

$E H A=$ Electrohydrostatic Actuator

$H T P B=$ Hydroxyl-terminated Polybutadiene

$N A S A=$ National Aeronautics and Space Administration

$P B A N=$ Polybutadiene Acrylonitrile

RSRM = Reusable Solid Rocket Motor

SIL $\quad=$ System Integration Laboratory

$T V C=$ Thrust Vector Control 